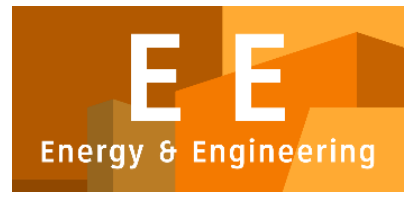

PAPER - OPEN ACCESS

\title{
Studi Eksperimental Analisa Kinematik Pengereman Mobil
}

\author{
Author : Muhammad Sabri \\ DOI $\quad: 10.32734 /$ ee.v1i2.247 \\ Electronic ISSN : :2654-7031 \\ Print ISSN : 2654-704X
}

Volume 1 Issue 1 - 2018 TALENTA Conference Series: Energy and Engineering

\section{(c)}

This work is licensed under a Creative Commons Attribution-NoDerivatives 4.0 International License.

Published under licence by TALENTA Publisher, Universitas Sumatera Utara
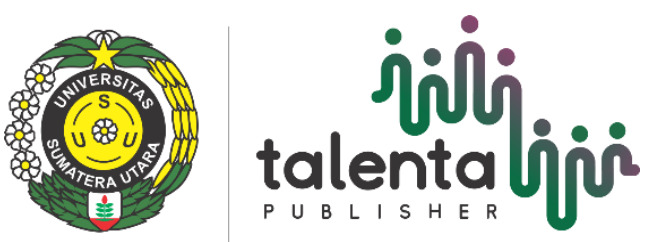
Available online at https://talentaconfseries.usu.ac.id

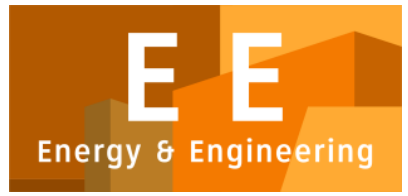

\title{
Studi Eksperimental Analisa Kinematik Pengereman Mobil
}

\author{
M. Sabri ${ }^{\mathrm{a}}$, Ardhian fauza ${ }^{\mathrm{b}}$ \\ ${ }^{a, b}$ Departemen Teknik Mesin, Fakultas Teknik, Medan, 20155, Universitas Sumatera Utara \\ sabrimesin@gmail.com, ardhian.fauza@yahoo.com
}

\begin{abstract}
Abstrak
Penelitian ini bertujuan untukmenemukan hubungan keterikatan antara parameter utama kinematik yang terdapat pada proses pengereman yaitu gaya, jarak dan waktu pada proses pengereman. Perbedaan pola dan karakteristik dari proses pengereman pada kendaraan dinilai sangat penting untuk diketahui disebabkan sistem rem merupakan sistem yang mempunyai peran besar terhadap keamanan dalam berkendara. Yang kemudian hasil penelitian menunjukan bahwa parameter gaya berbanding terbalik terhadap jarak dan waktu pengereman ( gaya $><$ jarak dan waktu). Sehingga kesimpulan utama dari hasil penelitian adalah karateristik pada proses pengereman mempunyai kecenderungan yang tidak jauh berbeda tetapi memiliki perubahan jarak dan waktu pengereman yang dapat berubah ubah pada setiap variasi gaya yang diberikan pada saat sebelum dan setelah sistem rem pada kendaraan diperbaiki.
\end{abstract}

Keywords: Hubungan; pengereman; gaya; jarak; waktu; karateristik; keamanan; berbanding terbalik; sebelum; sesudah

\section{Pendahuluan}

Sistem rem adalah sistem yang sangat penting keberadaannya pada kendaraan. brake / rem sendiri berfungsi untuk mengurangi kecepatan putaran pada roda kendaraan sehingga laju kendaraan menjadi stabil dan terkendali, akibat dari kendaraan yang tidak terkendali tentu sangat berbahaya bagi penumpang kendaraan itu sendiri. Sistem rem terdiri dari komponen - komponen yang menghubungkan langsung pusat kendali (pengemudi) ke roda kendaraan, diantaranya : pedal rem, master rem, selang hidrolik, kaliper, tapak rem, piringan cakram. Bagian - bagian ini sangat penting perannya pada kendaraan beroda. Masing - masing komponen pada sistem rem berfungsi untuk meneruskan gaya yang diberikan pengemudi saat menginjak pedal rem ke kaliper pada piringan cakram yang kemudian akan menyebabkan piston kaliper menjepit piringan cakram pada roda kendaraan, akibatnya kecepatan putar pada

Roda otomatis akan berkurang. Oleh karena itu sistem rem pada kendaraan sangat sensitif terhadap gaya yang diberikan pada pedal brake. Sistem brake hidrolik memanfaatkan sifat fluida cair, apabila fluida ini diberikan gaya/tekanan dalam ruang tertutup maka fluida akan menekan kesegala arah. Fluida yang diberikan gaya tersebut akan meneruskan gaya yang diterima (input) ke piston kaliper (output).

Berdasarkan perannya yang sangat penting dalam kendaraan maka hal ini lah yang melatar belakangi penulis untuk melakukan kajian eksperimental pada proses pengereman kendaraan. 


\section{Tujuan Penelitian}

Adapun tujuan penelitian yang terdapat pada pada studi eksperimental analisa kinematik pengereman mobil thaft daihatsu hiline yaitu sebagai berikut :

- Untuk mengetahui perbandingan antara parameter input (gaya dan kecepatan) yang diberikan pada sistem rem terhadap parameter output (jarak dan waktu).

- Untuk mengetahui karateristik dan pola perbandingan antara parameter input (gaya dan kecepatan) terhadap parameter output (jarak dan waktu)

- Untuk mengetahui performa sistem rem kendaraan mobil daihatsu thaft hiline sebelum dilakukan perbaikan dan setelah dilakukan perbaikan.

\section{Batasan Masalah}

Adapun batasan masalah yang terdapat pada penelitian studi eksperimental analisa kinematik pengereman mobil thaft daihatsu hiline yaitu sebagai berikut :

- Penelitian ini dilakukan hanya pada analisa kinematik pengereman kendaraan roda empat yaitu mobil daihatsu thaft hiline

- Penelitian ini dilakukan dengan pengujian pada kecepatan $10 \mathrm{~km} / \mathrm{jam}$ hingga $50 \mathrm{~km} / \mathrm{jam}$ dengan rentang 10 $\mathrm{km} / \mathrm{jam}$ setiap variasi parameter kecepatannya.

- Parameter output yang dilakukan pengukuran hanya pada parameter jarak dan waktu pengereman

- Faktor gesekan hanya pada keadaan jalan kering penelitian tidak dilakukan dengan kondisi jalan basah

- Kondisi permukaan jalan yaitu pada kondisi rata

- Laju kecepatan angin pada saat pengujian diabaikan.

\section{Manfaat Penelitian}

Adapun manfaat penelitian yang terdapat pada penelitian studi eksperimental analisa kinematik pengereman mobil thaft daihatsu hiline yaitu sebagai berikut :

- Untuk bidang aspek akademik penelitian ini dapat menjadi acuan sistem pengereman dibidang otomotif, juga dapat dikembangkan kedalam mata kuliah terkhusus konsentrasi maintenance/pemeliharaan misalnya : mata kuliah Codition Base Maintenance.

- Secara non akademis/praktis penelitian ini menjadi acuan untuk mengetahui karateristik hubungan antara gaya yang diberikan pada pedal rem terhadap fenomena kinematik pada pengereman sebelum dan setelah kendaraan diperbaiki.

\section{Tinjauan Pustaka}

Berdasarkan sistem prinsip kerjanya maka sistem rem dibagi menjadi 3 yaitu : sistem rem mekanik, sistem rem hidrolik, dan sistem rem pneumatik. Berdasarkan sistem kontrolnya maka sistem rem dibagi menjadi 3 yaitu : ABS (Antilock Brake System), EBD (Electronic Brake Distribution), BA/EBA (Brake Asistant/Emergency Brake Asistant). Berdasarkan tipe - tipenya maka rem dibagi menjadi 2 yaitu : rem cakram dan rem tromol.

Untuk lebih memahami sistem brake/rem yang terdapat pada kendaraan, berikut adalah tabel komponen komponen yang digunakan pada sistem brake/rem, beserta fungsinya, yaitu: 
Tabel. 1. Komponen - komponen sistem rem dan fungsinya

\begin{tabular}{|c|c|c|}
\hline No & Komponen & Fungsi \\
\hline 1 & Pedal rem & $\begin{array}{l}\text { Fungsi dari pedal rem adalah sebagai titik kontrol pengemudi dalam melakukan proses } \\
\text { pengereman, disebut titik kontrol karena saat melakukan pengereman maka pedal rem } \\
\text { haruslah diinjak oleh pengemudi. }\end{array}$ \\
\hline 2 & Booster rem & $\begin{array}{l}\text { Fungsi dari booster rem adalah meneruskan tekanan yang diterima oleh pedal rem ke } \\
\text { master silinder yang kemudian menekan fluida yang terdapat pada master silinder. }\end{array}$ \\
\hline 3 & Master silinder & Master silinder berfungsi untuk mengubah gerak pedal rem ke dalam tekanan hidolis \\
\hline 4 & $\begin{array}{l}\text { Katup Propotioning } \\
\text { (Katup Penyeimbang) }\end{array}$ & $\begin{array}{l}\text { Fungsi dari katup Propotioning atau katup penyeimbang adalah untuk menambah gaya } \\
\text { pengereman yang ada pada roda depan kendaraan }\end{array}$ \\
\hline 5 & $\begin{array}{l}\text { Flexible hose / selang } \\
\text { fleksibel }\end{array}$ & $\begin{array}{l}\text { Adalah komponen yang berfungsi untuk menghubungkan pipa rem dan rem roda untuk } \\
\text { mengimbangi gerakan suspensi. }\end{array}$ \\
\hline 6 & $\begin{array}{l}\text { Tuas rem parkir / rem } \\
\text { tangan }\end{array}$ & $\begin{array}{l}\text { Tuas rem parkir adalah komponen yang berfungsi untuk mengeremm roda kendaraan } \\
\text { belaknag secara mekanis melalui batang penghubung dan kabel. }\end{array}$ \\
\hline 7 & Kaliper & $\begin{array}{l}\text { Kaliper berfungsi untuk meneruskan tekanan yang di tranfer melalui selang fleksibel } \\
\text { dan kemudian menggerakan piston pada kaliper mendorong pad rem unutk menjepit / } \\
\text { menggesek piringan dan drum pada rem }\end{array}$ \\
\hline 8 & Pad rem / Kanvas rem & $\begin{array}{l}\text { Fungsi dari Pad rem / kanvas rem adalah sebagai media yang akan bergesekan dengan } \\
\text { piringan cakram ataupun drum rem untuk menghentikan laju putaran pada roda. }\end{array}$ \\
\hline 9 & Piringan Cakram & $\begin{array}{l}\text { Fungsi dari piringan cakram adalah sebagai media yang terdapat pada rotor / roda untuk } \\
\text { menciptakan gesekan yang akan menghentikan laju putaran dari rem. }\end{array}$ \\
\hline
\end{tabular}

\section{Metode Penelitian}

Metode yang digunakan pada penelitian ini adalah dengan melakukan identifikasi keperluan yang ada, kemudian menetapkan spesifikasi sistem pengereman yang akan di uji hingga pengambilan kesimpulan akhir berdasarkan hasil penelitian. Untuk lebih jelasnya tentang prosedur yang dilakukan pada pengujian eksperimental penilaian analisa kinematik pada sistem rem mobil dapat dilihat pada diagram alir berikut ini.

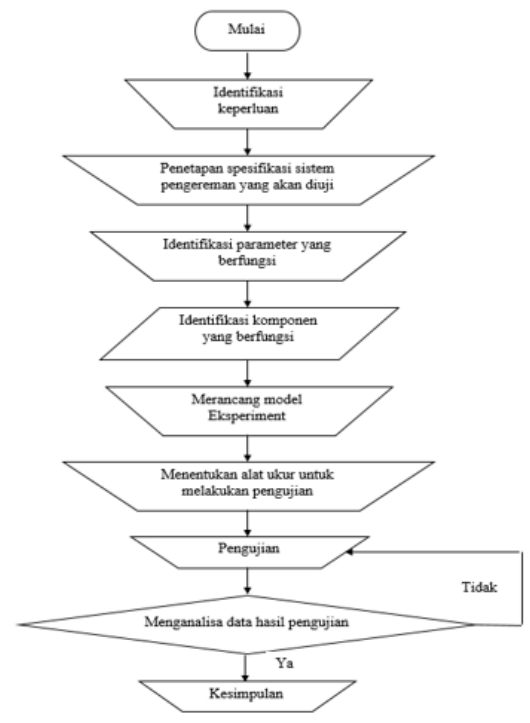

Gambar. 1. Diagram alir penelitian 


\subsection{Alat, Bahan, dan Objek Penelitian}

\subsubsection{Timbangan Pegas}

Timbangan pegas adalah alat pengukur massa benda berdasarkan gravitasi, alat ini digunakan untuk mengukur tekanan gaya yang diberikan pada pedal rem.

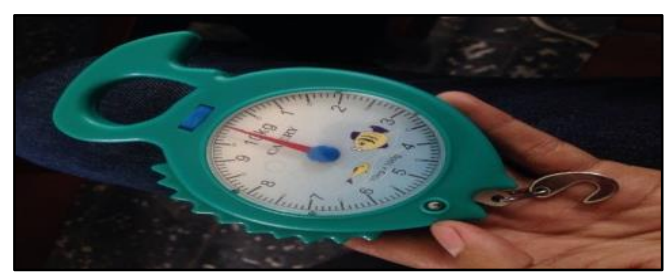

Gambar. 2. Timbangan Pegas

\subsubsection{Pegas}

Pegas digunakan untuk menyesuaiakan tekanan yang diberikan pada pedal ke sensor timbangan pegas, hal ini dilakukan karena pertambahan panjang pada sensor dengan pertambahan jarak pedal ke alat pengukur yang memiliki perbadingan yang berbeda.

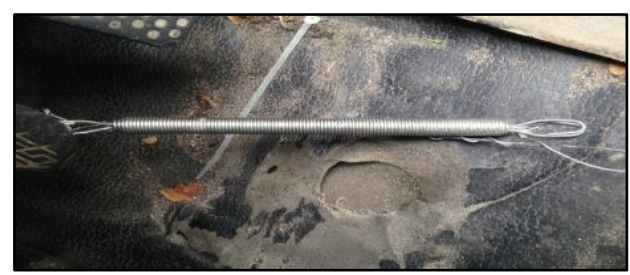

Gambar. 3. Pegas

\subsubsection{Tang Kawat}

Tang digunakan untuk memotong kawat dan mengikat kawat pada set up dinamometer gaya yang diberikan pada pedal rem, berikut adalah tang yang digunakan.

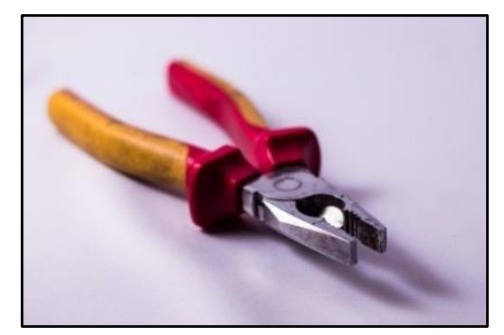

Gambar. 4. Tang Kawat

\subsubsection{Pita Meter}

Meteran digunakan untuk mengukur jarak yang ditempuh kendaraan dalam melakukan pengereman dengan variasi kecepatan dan gaya yang diberikan pada pedal gas. 


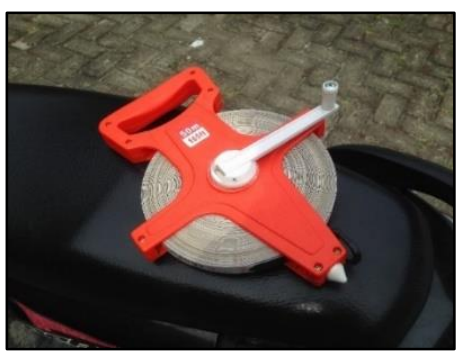

Gambar. 5. Pita Meter

\subsubsection{Stopwatch}

Stopwatch digunakan untuk menghitung waktu yang dibutuhkan kendaraan dari saat proses pengereman dimulai dalam kecepatan tertentu hingga kendaraan berhenti total $(0 \mathrm{Km} / \mathrm{jam})$.

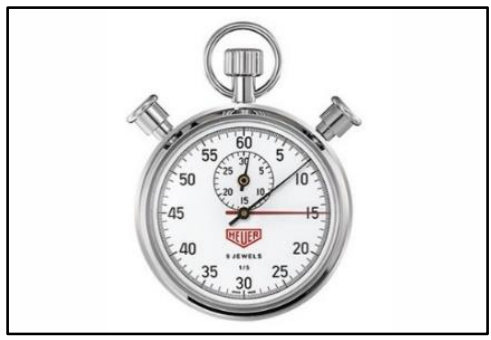

Gambar. 6. Stopwatch

Untuk melakukan eksperimen maka selain dibutuhkan alat maka dibutuhkan juga bahan, berikut adalah bahan yang digunakan dalam eksperimen, yaitu :

\subsubsection{Bahan Bakar Minyak (solar)}

Untuk melakukan pegujian analisa kinematik maka tentu dibutuhkan bahan bakar minyak (solar) untuk menjalankan mobil, berikut adalah bahan bakar solar.

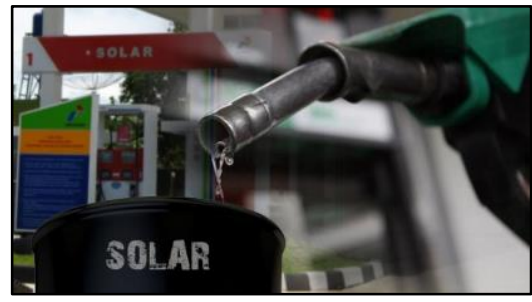

Gambar. 7. Solar

\subsubsection{Kawat}

Kawat digunakan sebagai bahan penelitian dalam mekanisme dinamometer serta instrument penahan tekanan gaya pada pedal rem, berikut adalah kawat yang digunakan. 


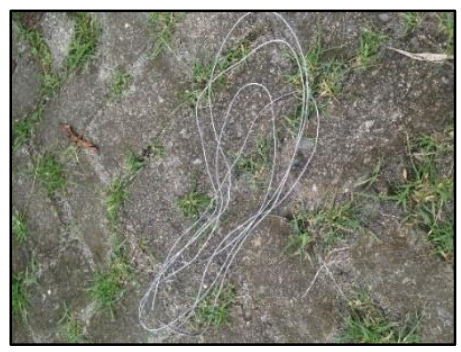

Gambar. 8. Kawat

Setelah melengkapi alat dan bahan maka pengujian analisa kinematik dilakukan pada objek penelitian yaitu mobil daihatsu thaft hiline.

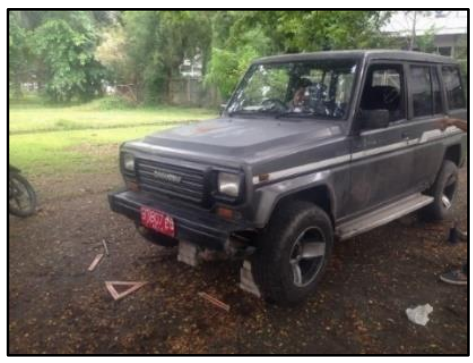

Gambar. 9. Mobil Daihatsu Thaft Hiline

\subsection{Membangun Setup Pengujian}

Untuk membangun setup pengujian dibutuhkan jalan yang kosong dan steril untuk melakukan pengujian analisa kinematik pengereman, dalam membangun setup pengujian dibagi menjadi dua yaitu setup dinamometer dan setup pengujian analisa kinematik untuk memilih jalan yang kira - kira dapat dilakukan pengujian.

\subsubsection{Setup Dinamometer pada Pedal Rem}

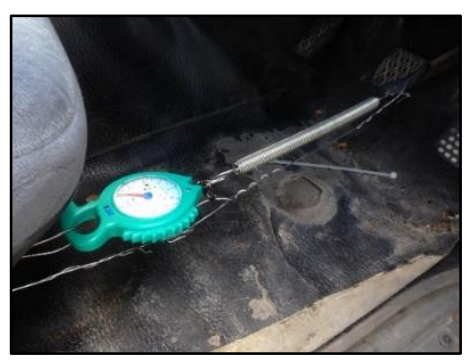

Gambar. 10. Setup Dinamometer 


\subsubsection{Setup Jalan}

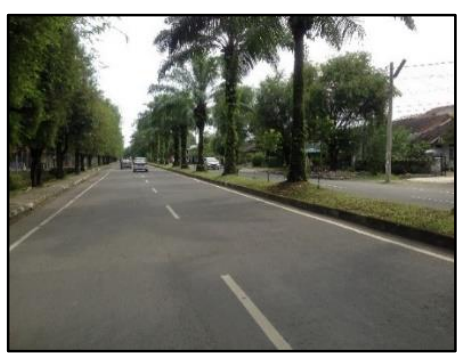

Gambar. 11. Jalan Tri Dharma Kampus USU

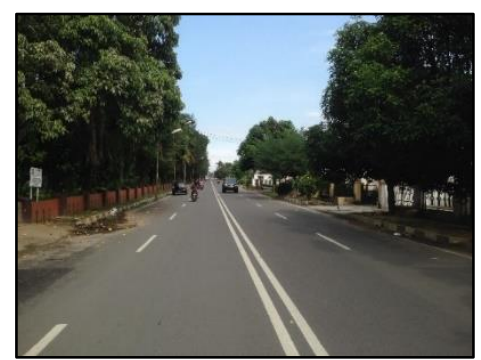

Gambar. 12. Jalan Dr. Sofyan Kampus USU

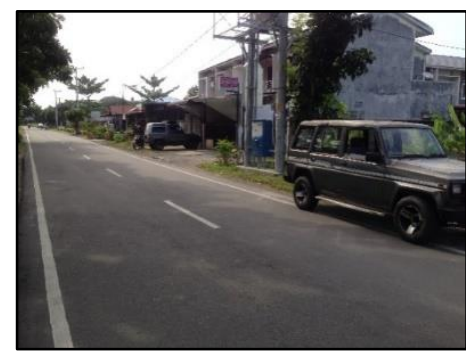

Gambar 13. Jalan Pasar II Setiabudi, Medan

\subsection{Tahapan Pengujian}

Ada beberapa langkah yang dilakukan dalam tahapan pengujian studi eksperimental penilaian analisa kinematik pada kendaraan thaft hiline tahun 1998, yaitu sebagai berikut :

- Persiapkan alat dan bahan yang akan digunakan dalam uji eksperimental

- Persiapkan objek uji eksperimental yaitu daihatsu thaft hiline

- Persiapkan dinamometer untuk pengujian pada variasi gaya pertama yaitu $8 \mathrm{~N}$.

- Nyalakan mesin mobil

- Kemudikan mobil melaju dengan kecepatan $10 \mathrm{Km} / \mathrm{jam}$

- Biarkan mobil melaju dengan kecepatan $10 \mathrm{~km} / \mathrm{jam}$ dalam 3 detik

- Injak pedal rem dengan gaya yang telah ditentukan yaitu $8 \mathrm{~N}$

- Ukur jarak yang ditempuh kendaraan saat pengereman dilakukan hingga kendaraan berhenti $(\mathrm{V}=0)$

- Hitung waktu yang dibutuhkan kendaran dari pengereman mulai dilakukan hingga kendaraan berhenti $(\mathrm{V}=0)$

- Ulangi pengujian pada variasi kecepatan kedua $20 \mathrm{~km} / \mathrm{jam}$, ketiga $30 \mathrm{~km} / \mathrm{jam}$ dan seterusnya, kemudian pada variasi gaya kedua $12 \mathrm{~N}$, ketiga $16 \mathrm{~N}$ dan seterusnya.

- Catat hasil pengujian sampel pertama hingga terakhir dan ambil kesimpulan.

\section{Hasil dan Pembahasan}

Untuk menentukan hasil penelitian maka digunakan dua kategori parameter pengereman yaitu service brake dan emergency brake, dua kategori ini bertujuan untuk melihat hubungan antara parameter input dan output pada kedua kategori pengereman serta untuk melakukan validasi kategori standart pengereman pada tipe pengereman emergency brake.

Untuk mencegah human error pada data hasil pengujian maka pengujian analisa kinematik dilakukan sebanyak 3 kali setiap variasi parameternya.

Untuk melakukan validasi jarak pengereman maka diambil data emergency brake yang didaptakan berdasarkan hasil eksperimen. berikut adalah validasi standart kategori jarak pengereman berdasarkan hasil eksperimen 


\subsection{Data jarak pengereman emergency brake sebelum dilakukan perbaikan pada kendaraan}

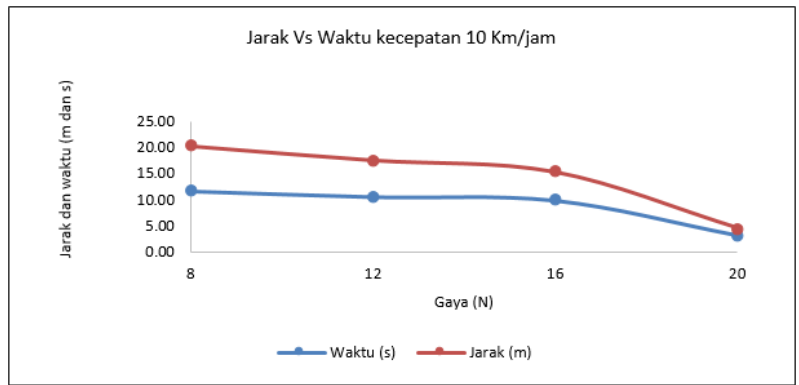

Gambar. 14. Grafik jarak vs waktu kec. 10 km/jam

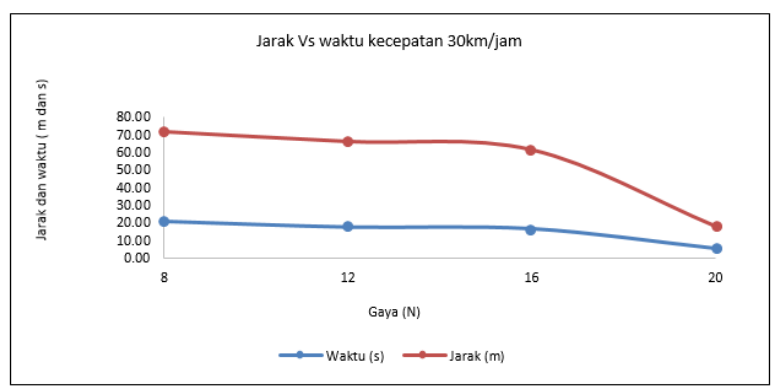

Gambar. 16. Grafik jarak vs waktu kec. 30 km/jam

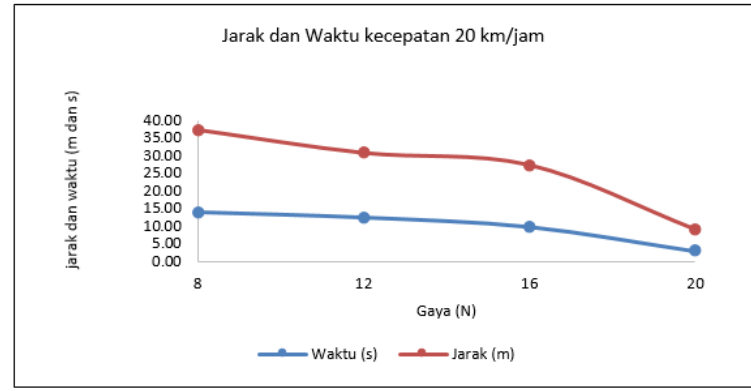

Gambar. 15. Grafik jarak vs waktu kec. 20 km/jam

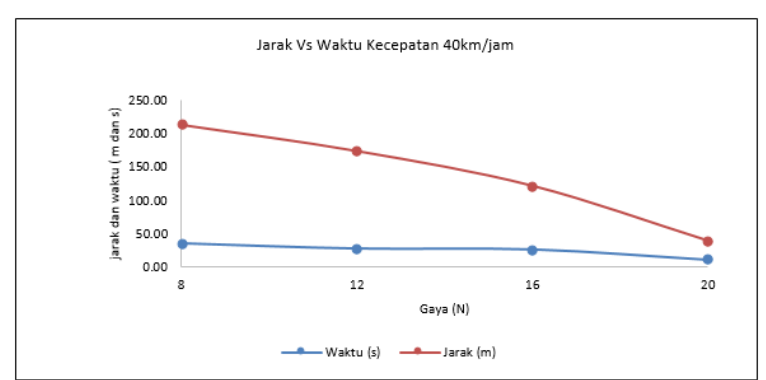

Gambar. 17. Grafik jarak vs waktu kec. 40 km/jam

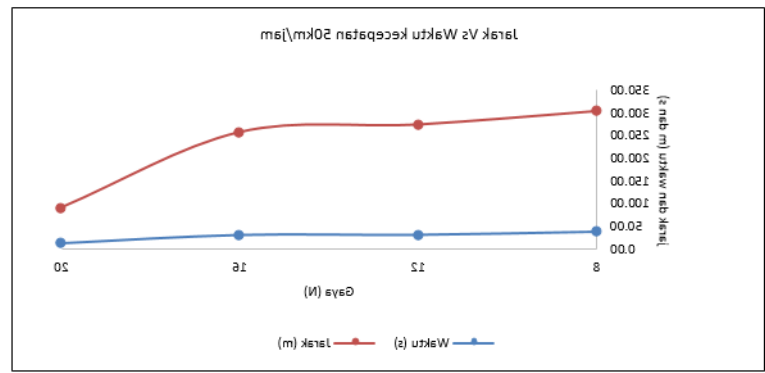

Gambar. 18. Grafik jarak vs waktu kec. 50 km/jam

\subsection{Data jarak pengereman emergency brake setelah dilakukan perbaikan pada kendaraan}

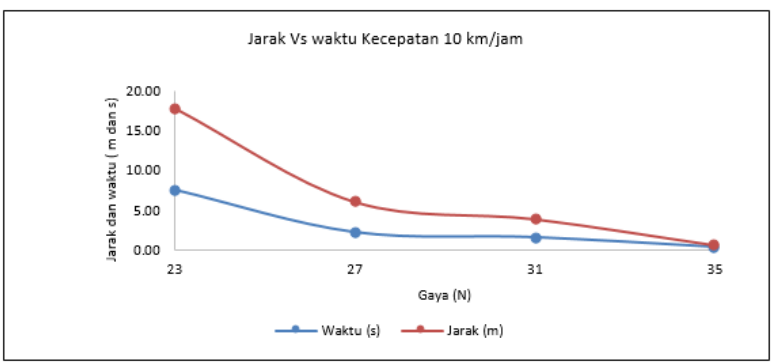

Gambar. 19. Grafik jarak vs waktu kec. 10 km/jam

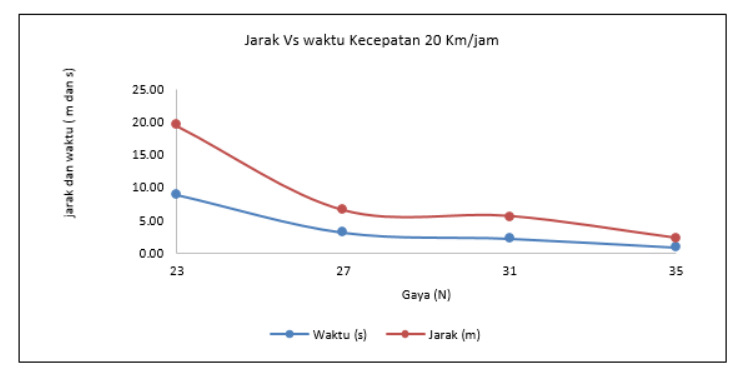

Gambar. 20. Grafik jarak vs waktu kec. 20 km/jam 


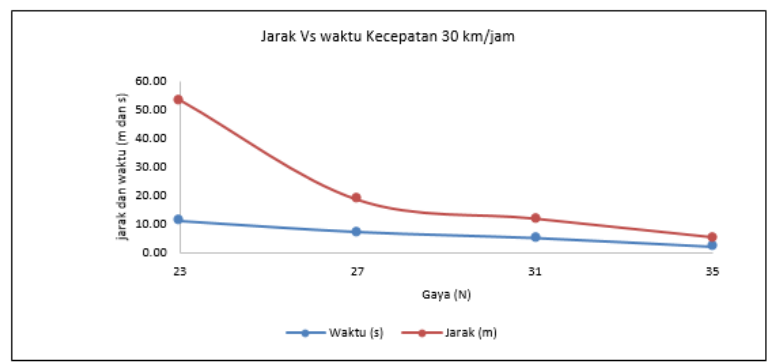

Gambar. 21. Grafik jarak vs waktu kec. 30 km/jam

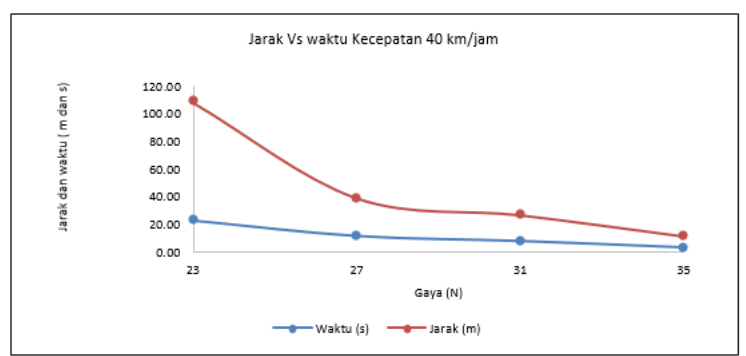

Gambar. 22. Grafik jarak vs waktu kec. 40 km/jam

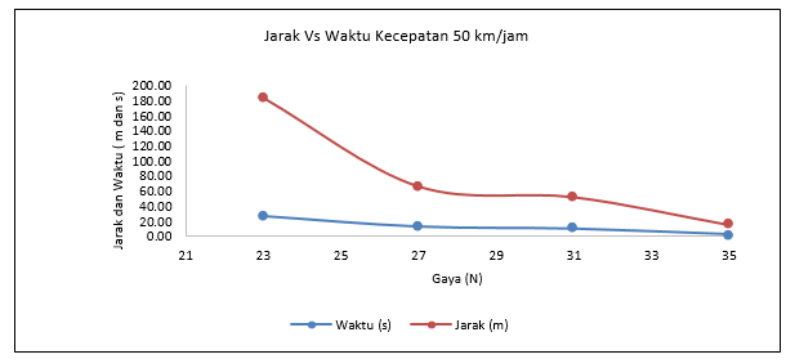

Gambar. 23. Grafik jarak vs waktu kec. 50 km/jam

\section{Kesimpulan}

Berdasarkan eksperimen hasil pengujian analisa kinematik sebelum dan setelah dilakukan perbaikan pada mobil Thaft Daihatsu Hiline maka dapat diambil kesimpulan yaitu sebagai berikut :

- Berdasarkan data hasil eksperimen analisa kinematik pada kendaraan maka didapatkan bahwa gaya yang di berikan pada pedal rem berbanding terbalik dengan jarak dan waktu pengereman

- Data hasil eksperimen menunjukan bahwa karateristik proses pengereman pada setiap kecepatan mempunyai tren/kecenderungan yang sama

- Data hasil eksperimen menunjukan bahwa perubahan parameter jarak dan waktu pengereman yang signifikan cenderung terdapat pada gaya $16 \mathrm{~N}$ dan $20 \mathrm{~N}$ sebelum dilakukan perbaikan pada sistem rem kendaraan

- Data hasil eksperimen menunjukan bahwa perubahan parameter jarak dan waktu pengereman yang signifikan terdapat pada gaya $23 \mathrm{~N}$ dan $27 \mathrm{~N}$ setelah dilakukan perbaikan pada sistem rem kendaraan

- Data hasil pengujian menunjukan bahwa performa sistem rem pada kendaraan mengalami peningkatan performa yang signifikan setelah dilakukan perbaikan pada sistem rem kendaraan

\section{Saran}

Berdasarkan hasil eksperimental pengujian analisa kinematik pada pengereman kendaraan mobil daihatsu thaft hiline, maka saran yang dapat diberikan adalah sebagai berikut :

- Eksperimen pengujian analisa kinematik sebaiknya dilakukan di jalan yang lurus dan panjang serta jarang diakses sehingga keselamatan dalam pengujian lebih terjamin dan hasil yang didapatkan menjadi lebih bervariasi pada parameter kecepatan

- Untuk Mendapatkan hasil yang lebih maksimal dan akurat maka pengujian analisa kinematik pengereman sebaiknya dilakukan dengan menggunakan alat pengukur yang lebih akurat pada pengukuran pedal rem yaitu menggunakan force detector.

- Untuk pengujian analisa kinematik pengereman selanjutnya dilakukan dengan variasi kecepatan yang lebih banyak sehingga mendapatkan sampel yang lebih bervariasi dalam eksperimen 
- Untuk menunjang kelengkapan data sebaiknya dilakukan penelitian simulasi komputasi untuk analisa kinematik pada pengereman kendaraan mobil thaft daihatsu hiline sehingga hasil pengujian eksperimen menjadi lebih akurat

\section{Daftar Pustaka}

[1] Setiyon, Rohmad. (2015). "Analisis Gaya Pengereman Pada Mobil Nasional Mini Truck”. Surakarta. Universitas Muhamnadiyah surakarta

[2] Yunuar. Satyadarma, Dita. Noerdin Burhan. 2010. "Analisis Gaya Pada Rem Cakram (Disk Brake) Untuk Kendaraan Roda Empat”. Jakarta. Universitas Gunadarma

[3] Putra, Purnama. (2012). “Analisis Sistem Rem Depan Pada Kijang Innova Tipe V Tahun 2004”. Bandung. Universitas Pendidikan Indonesia.

[4] Layton, Robert. Dixon, Karen. "Stoping Sight Distance". (2012). Amerika Serikat. Oregon State University

[5] Evans, Micheal. (2011). "Braking Distance". Australia. Australian mathematic Sciences Institute.

[6] Munardi, Dhika. (2016). "Desain Dan Analisis Perancangan Sistem Pengereman Dan Geometri Roda Pada Gokart 150cc DOHC". Yogjakarta. Universitas Muhammadiyah Yogjakarta

[7] Grelbe, Poul. (2007). "Braking Distance Friction and Behavior”. Denmark. Trafitec Scion - DTU Diplomvej bygning 3762800 Kgs Lyngby. 